\title{
Rocky Mountain spotted fever encephalitis
}

Michael J. Bradshaw, MD

Kathryn B. Lalor, MD

NgocHanh Vu, MD

Sumit Pruthi, MBBS

Karen C. Bloch, MD, $\mathrm{MPH}$

\section{Correspondence to}

Dr. Bradshaw:

Michael.j.bradshaw@vanderbilt. edu

Supplemental data at Neurology.org
A 27-month-old previously healthy boy developed irritability and a fever the day after getting his 2-year vaccinations. Three days later, he developed a centripetally spreading petechial rash. A tick was removed from his neck. He was taken to an outside hospital several times over the course of 3-4 days and was discharged with amoxicillin the first time and ceftriaxone on a subsequent visit. Eight days into his illness, he developed depressed level of consciousness and had what was described as a generalized clonic seizure. He was intubated with paralytics and fentanyl and transferred to our hospital for evaluation and management. The remaining history was unremarkable.

Several hours after intubation and on no sedation, the patient was rigid with extensor posturing of all extremities in response to noxious stimulation but had intact brainstem reflexes. Reflexes were increased throughout with bilateral Babinski sign. He had a third heart sound, enlarged liver, and diffuse petechiae (figure, A). The remaining examination was unremarkable.

The patient had leukocytosis to $36 \times 10^{3} / \mu \mathrm{L}$ (reference range 4-14.6), anemia with hemoglobin $8.9 \mathrm{~g} / \mathrm{dL}$ (10.5-13.5), and thrombocytopenia with platelets 76 $\times 10^{3} / \mu \mathrm{L}(150-400)$. Electrolytes and renal function were normal. Aminotransferases were elevated, with aspartate aminotransferase $165 \mathrm{U} / \mathrm{L}(21-44)$ and alanine aminotransferase $56 \mathrm{U} / \mathrm{L}$ (9-25); bilirubin and alkaline phosphatase were normal. Lactate was elevated to $3.0 \mathrm{mmol} / \mathrm{L}(0.2-2.2)$. Troponin was elevated to $0.17 \mathrm{ng} / \mathrm{mL}(<0.03)$ with brain natriuretic hormone elevated to $2,362 \mathrm{pg} / \mathrm{mL}(10-100)$. C-reactive protein was elevated to $100 \mathrm{mg} / \mathrm{L}(0.1-1)$.

EEG demonstrated frequent but discreet seizures arising from both the right temporal and left parietooccipital areas consistent with subclinical status epilepticus. The patient was given $0.1 \mathrm{mg} / \mathrm{kg}$ IV lorazepam and loaded with levetiracetam $60 \mathrm{mg} / \mathrm{kg} \mathrm{IV}$, which aborted the seizures. This was followed by $30 \mathrm{mg} / \mathrm{kg}$ IV levetiracetam BID. Brain MRI demonstrated multifocal, punctate diffusion-restricting lesions that were hypointense on apparent diffusion coefficient and hyperintense on fluid-attenuated inversion recovery, a pattern consistent with the starry sky pattern (figure).
Lumbar puncture was grossly bloody without xanthochromia, 3,250 leukocytes/ $\mu \mathrm{L}$ (corrected for blood contamination of $\mathrm{CSF}=1,830$ cells $/ \mu \mathrm{L}$ ), $78 \%$ neutrophils, $2.40 \times 10^{6}$ erythrocytes $/ \mu \mathrm{L}$, glucose $76 \mathrm{mg} / \mathrm{dL}$ (45-75), protein $1,317 \mathrm{mg} / \mathrm{dL}$ (15-40). Echocardiogram demonstrated severely depressed left ventricular wall motion and moderately depressed right ventricular wall motion consistent with myocarditis given the patient's laboratory findings. He was treated empirically with vancomycin, ceftriaxone, and doxycycline. This regimen was narrowed to doxycycline when Rickettsia immunoglobulin $\mathrm{M}$ returned at $>1: 1,024$ with immunoglobulin $G<1: 64$ by immunofluorescence assay. All other infectious studies were negative (supplemental data at Neurology.org).

Over the course of a week, the patient's laboratory studies normalized. By 2 weeks, his myocarditis had resolved and heart function returned to normal by echocardiography. Two months after discharge, he was awake, alert, and interactive, but not speaking. He was able to sit independently, crawl, and transfer objects between hands and to his mouth, but needed a gastric tube for feeding support.

DISCUSSION Rocky Mountain spotted fever (RMSF) is a life-threatening infection caused by the obligate intracellular bacterium Rickettsia rickettsii and is the most common tick-borne rickettsial infection in the United States. ${ }^{1}$ After salivary inoculation from a feeding tick, the bacteria disseminate and infect the endothelial and vascular smooth muscle cells in the brain, skin, liver, lungs, kidneys, and gastrointestinal tract, which leads to the respective disease manifestations. The illness is most often reported in the summer months and the highest incidence rates are in Tennessee, Delaware, Missouri, Arkansas, North Carolina, and Oklahoma, but it occurs across the United States (cdc.gov/rmsf/stats/index.html). The untreated mortality rate is over $70 \%$, although early antibiotics reduce mortality to as low as $0.5 \%{ }^{2}$ Children and the elderly are at the highest risk of death and survivors may have severe sequelae such as limb amputation, deafness, and cognitive deficits.

From the Departments of Neurology (M.J.B., N.V.) and Medicine (Infectious Disease) and Health Policy (K.C.B.), Vanderbilt University Medical Center; and the Department of Pediatrics, Division of Pediatric Neurology (K.B.L.), and Pediatric Neuroradiology (S.P.), Monroe Carell, Jr. Children's Hospital at Vanderbilt, Nashville, TN.

Go to Neurology.org for full disclosures. Funding information and disclosures deemed relevant by the authors, if any, are provided at the end of the article. 

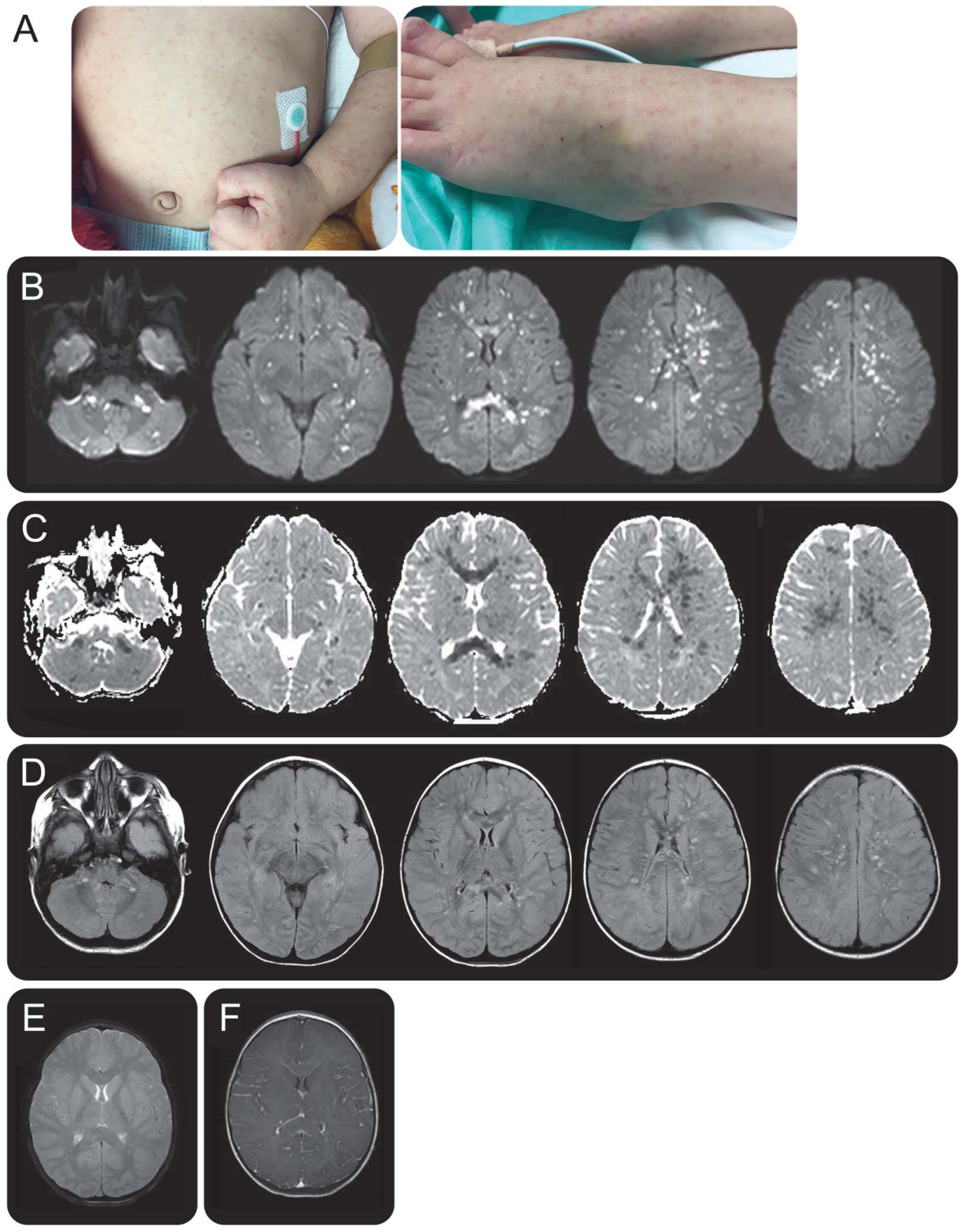

(A) The skin was covered with petechial lesions. (B) Diffusion-weighted imaging (DWI) demonstrates starry sky pattern of restricted diffusion, which correlates with lesions on (B) apparent diffusion coefficient (ADC) sequences. (C) T2 fluid-attenuated inversion recovery reveals hyperintense lesions correlating with those seen on DWI/ADC. (D) No hemorrhages are observed on gradient echo. (E) There are no contrast-enhancing lesions on T1 images taken after contrast administration.

Symptoms of RMSF include fever, malaise, headache, myalgias and arthralgias, abdominal pain, nausea/vomiting, and photophobia. The classic triad of fever, headache, and rash is rarely present in the first 3 days of illness and misdiagnosis of viral infection is common. ${ }^{1,3}$ The triad becomes apparent in $60 \%$ $70 \%$ of patients within the first 2 weeks of illness. ${ }^{1}$ Rash typically develops between 2 and 5 days after fever, and is initially maculopapular in appearance, progressing to petechiae, or less frequently purpura. ${ }^{1}$

Neurologic manifestations. Neurologic manifestations are common in patients with RMSF and range from headache, behavioral abnormalities, meningismus, and photophonophobia to more serious neurologic manifestations such as amnesia, aphasia, hearing loss, 


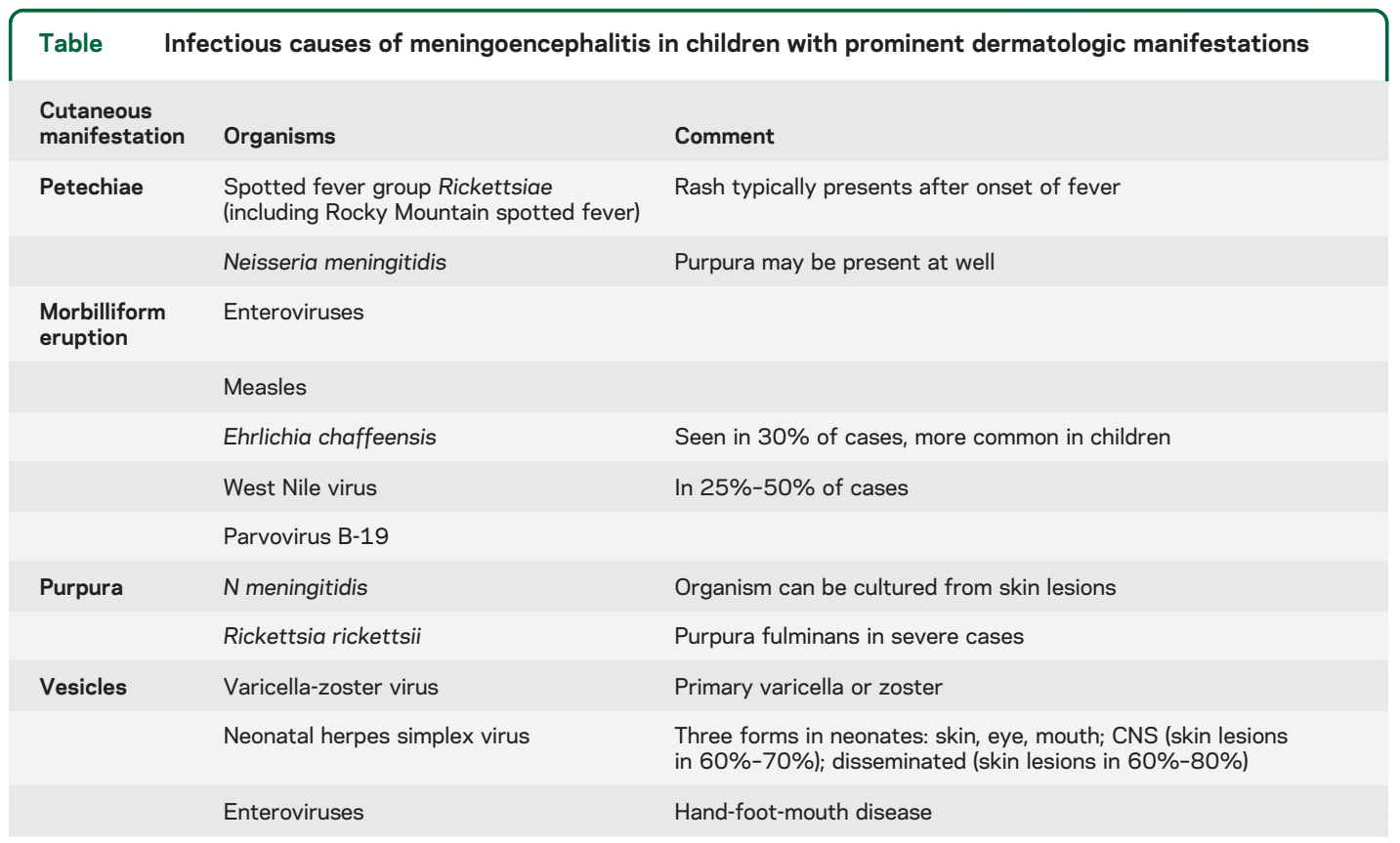

ataxia, seizures, and encephalitis/coma. ${ }^{4,5}$ Neurologic involvement including encephalitis is associated with higher mortality rates, which can be as high as $88 \%$ for comatose patients. ${ }^{3}$ Encephalitis is associated with infiltration of the perivascular spaces in the brain (Virchow-Robin spaces) by lymphocytes, macrophages, and polymorphonuclear lymphocytes at autopsy. ${ }^{6}$

Diagnosis of RMSF. Diagnosis of RMSF is challenging as the presentation is nonspecific, and serologic testing may be negative at the time of treatment. Failure to consider the diagnosis leads to delays in treatment, with resultant increased mortality. ${ }^{2}$ Therefore, any clues to the diagnosis are important for prompt recognition of this potentially fatal infection. Antibodies usually do not develop until roughly a week after exposure, which limits the clinical utility of serologic testing early in the course of the infection. PCR or immunohistochemistry performed on skin biopsy specimens may provide a diagnosis during the acute illness, and may be indicated when serologic testing is negative.? The current gold standard test is the indirect fluorescent antibody test, which is highly sensitive and specific for rickettsioses but does not distinguish among the rickettsiae. Therefore, in the early phase of illness, a high clinical suspicion, appropriate historical and examination findings, and supportive laboratory values are important. Nonspecific but helpful laboratory findings include thrombocytopenia, elevated aminotransferases, creatinine kinase, and hyponatremia. ${ }^{1}$ CSF typically demonstrates a moderate polymorphonuclear or lymphocytic pleocytosis with $<100$ cells $/ \mu \mathrm{L}$, moderately elevated protein (100-200), and normal glucose. 5 The differential diagnosis for a patient with rash and encephalomeningitis is broad (table).
MRI findings in RMSF encephalitis. There is very little literature on the MRI findings in RMSF. ${ }^{8}$ Bonawitz et al. ${ }^{9}$ reported the largest series to date with $34 \mathrm{pa}-$ tients, among whom only 6 had MRI studies. Four of these were abnormal: 1 patient had "prominent perivascular spaces," 1 had focal arterial infarctions, 1 had diffuse edema, and 1 had meningeal enhancement. Baganz et al. ${ }^{6}$ reported a single case of RMSF with neurologic manifestations wherein a 45-year-old woman with encephalitis was noted to have punctate T2 hyperintense lesions disseminated throughout the white matter on MRI that resolved with treatment and resolution of neurologic signs and symptoms. White matter infarctions and leptomeningitis have also been described.

The starry sky pattern on MRI. We previously reported a case of a 32-month-old boy with RMSF encephalitis with MRI findings resembling a starry sky pattern on T1, T2, and diffusion-weighted imaging. ${ }^{10}$ Since then, at least 2 other cases with the starry sky pattern on MRI have been reported. Autopsy of patients who died of RMSF encephalitis has demonstrated gliosis, demyelination, and necrosis in affected areas. ${ }^{9}$ It has been suggested that this pattern represents perivenular vasculitis; however, the precise underlying mechanisms are not clear and the absence of parenchymal enhancement indicates that the blood-brain barrier is intact.

While the starry sky pattern is highly suggestive of RMSF in the proper clinical context, it is not entirely specific to this entity. A similar-appearing pattern on diffusion-weighted imaging (DWI) can be seen in the setting of Nipah virus encephalitis, diffuse axonal injury, fat embolism, or other thromboembolic phenomenon. 
Similarly, multiple T2 hyperintense foci in similar distribution without associated DWI changes can be seen in such etiologies as Lyme disease, cryptococcus, neurocysticercosis, viral encephalitis, tuberculous meningitis, air embolism, and rarely mucopolysaccharidoses. ${ }^{8}$ We suggest that in cases of encephalitis with MRI consistent with the starry sky pattern on DWI, empiric treatment with doxycycline should be considered. This is especially prudent in the presence of supportive laboratory studies (described above) even while the specific diagnostic evaluation for RMSF is underway, given the high casefatality rate among untreated patients.

Treatment. When there is high clinical concern for RMSF, treatment should not await laboratory confirmation. Tetracyclines and chloramphenicol are the only antibiotics with definite efficacy for RMSF. ${ }^{1}$ Doxycycline is the preferred first-line agent, even in children. The dosing in children is $2.2 \mathrm{mg} / \mathrm{kg}$ divided into twice daily dosing up to $100 \mathrm{mg}$ BID for a minimum of 5-7 days or until the patient is afebrile for at least 2-3 days. IV therapy is recommended in cases with neurologic involvement.

RMSF is a tick-borne infection caused by $R$ rickettsii that leads to multiorgan vasculitis and can progress rapidly to death if not recognized and treated. Encephalitis and other neurologic manifestations are associated with severe illness and worse outcomes. The starry sky pattern, which consists of multifocal, punctate areas of diffusion restriction predominantly distributed in the white matter, is common in RMSF encephalitis in children, but the sensitivity and specificity is unknown. This finding should serve as a clue to the diagnosis in the right clinical context, which includes rash, headache, fever, elevated aminotransferases, anemia, and thrombocytopenia. In patients with encephalitis who have the starry sky pattern on MRI, consideration should be given to empirical treatment with doxycycline while the diagnostic evaluation is underway.

\section{AUTHOR CONTRIBUTIONS}

Michael J. Bradshaw: literature review, clinical and imaging review, manuscript preparation/editing. Kathryn B. Lalor: clinical and imaging review, manuscript preparation/editing. NgocHanh Vu: manuscript review, editing. Sumit Pruthi: neuroimaging interpretation. Karen C. Bloch: manuscript review/editing.

\section{STUDY FUNDING}

No targeted funding reported.

\section{DISCLOSURE}

The authors report no disclosures relevant to the manuscript. Go to Neurology.org for full disclosures.

\section{REFERENCES}

1. Dantas-Torres F. Rocky Mountain spotted fever. Lancet Infect Dis 2007;7:724-732.

2. Dahlgren FS, Holman RC, Paddock CD, Callinan LS, McQuiston JH. Fatal Rocky Mountain spotted fever in the United States, 1999-2007. Am J Trop Med Hyg 2012;86:713-719.

3. Helmick CG, Bernard KW, D’Angelo LJ. Rocky Mountain spotted fever: clinical, laboratory, and epidemiological features of 262 cases. J Infect Dis 1984;150:480-488.

4. Bleck TP. Central nervous system involvement in rickettsial diseases. Neurol Clin 1999;17:801-812.

5. Buckingham SC, Marshall GS, Schutze GE, et al. Clinical and laboratory features, hospital course, and outcome of Rocky Mountain spotted fever in children. J Pediatr 2007; 150:180-184, 184.e181.

6. Baganz MD, Dross PE, Reinhardt JA. Rocky Mountain spotted fever encephalitis: MR findings. AJNR Am J Neuroradiol 1995;16:919-922.

7. Chapman AS, Bakken JS, Folk SM, et al. Diagnosis and management of tickborne rickettsial diseases: Rocky Mountain spotted fever, ehrlichioses, and anaplasmosis: United States: a practical guide for physicians and other health-care and public health professionals. MMWR Recomm Rep 2006;55:1-27.

8. Akgoz A, Mukundan S, Lee TC. Imaging of rickettsial, spirochetal, and parasitic infections. Neuroimaging Clin N Am 2012;22:633-657.

9. Bonawitz C, Castillo M, Mukherji SK. Comparison of CT and MR features with clinical outcome in patients with Rocky Mountain spotted fever. AJNR Am J Neuroradiol 1997;18:459-464.

10. Crapp S, Harrar D, Strother M, Wushensky C, Pruthi S. Rocky Mountain spotted fever: "starry sky" appearance with diffusion-weighted imaging in a child. Pediatr Radiol 2012;42:499-502. 


\section{Neurology}

\section{Child Neurology: Rocky Mountain spotted fever encephalitis \\ Michael J. Bradshaw, Kathryn B. Lalor, NgocHanh Vu, et al. Neurology 2017;88;e92-e95 \\ DOI 10.1212/WNL.0000000000003722}

\section{This information is current as of March 13, 2017}

\section{Updated Information \& Services}

Supplementary Material

References

Subspecialty Collections

Permissions \& Licensing

Reprints including high resolution figures, can be found at: http://n.neurology.org/content/88/11/e92.full

Supplementary material can be found at: http://n.neurology.org/content/suppl/2017/03/13/WNL.0000000000003 722.DC1

This article cites 10 articles, 1 of which you can access for free at: http://n.neurology.org/content/88/11/e92.full\#ref-list-1

This article, along with others on similar topics, appears in the following collection(s):

All Pediatric

http://n.neurology.org/cgi/collection/all_pediatric

Encephalitis

http://n.neurology.org/cgi/collection/encephalitis

MRI

http://n.neurology.org/cgi/collection/mri

Information about reproducing this article in parts (figures,tables) or in its entirety can be found online at:

http://www.neurology.org/about/about_the_journal\#permissions

Information about ordering reprints can be found online:

http://n.neurology.org/subscribers/advertise

Neurology ${ }^{\circledR}$ is the official journal of the American Academy of Neurology. Published continuously since 1951 , it is now a weekly with 48 issues per year. Copyright @ 2017 American Academy of Neurology. All rights reserved. Print ISSN: 0028-3878. Online ISSN: 1526-632X.

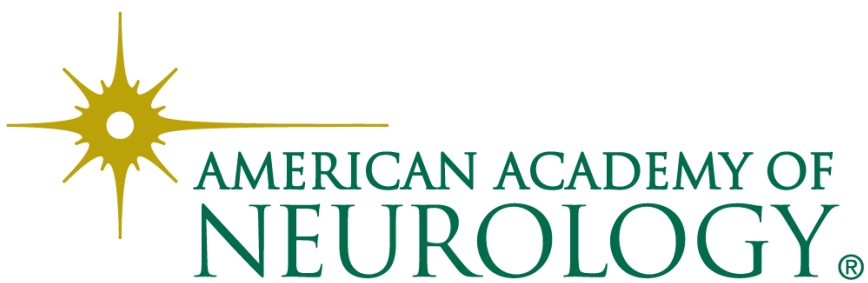

